\title{
Evaluation of gamma and neutron irradiation effects on the properties of mica film capacitors
}

\author{
RAJESH ROY and ARUN PANDYA* \\ Defence Laboratory, Ratanada Palace, Jodhpur 342 011, India
}

MS received 30 November 2004

\begin{abstract}
We present an investigation of gamma and neutron radiation effects on mica film capacitors from an electrical point of view. We have studied quantitatively the effects of gamma and neutron irradiation on mica film capacitors of thickness, 20 and $40 \mu \mathrm{m}(0.7874$ and $1.5748 \mathrm{mil})$ with two different areas, 01 and $04 \mathrm{~cm}^{2}$. The capacitance has been measured at room temperature in the frequency range $100 \mathrm{~Hz}-10 \mathrm{MHz}$. Negligible change in the capacitance due to high gamma dose of ${ }^{60} \mathrm{Co}, 15 \mathrm{kGy}$ at dose rate $0 \cdot 25 \mathrm{kGy} / \mathrm{h}$, has been observed. However, appreciable change in the capacitance has been observed due to low doses of fast neutrons (cumulative dose, $115 \mathrm{cGy}$ ) with flux $\sim 9.925 \times 10^{7}$ neutrons $/ \mathrm{cm}^{2} \mathrm{~h}$ from ${ }^{252} \mathrm{Cf}$ neutron source of fluence, $2.5 \times 10^{7}$ neutrons/s. We have also observed that the impact of gamma and neutron irradiation is more at frequencies higher than $10 \mathrm{kHz}$. These results show that the mica capacitors do not show any radiation response below $10 \mathrm{kHz}$.

The study shows the radiation response of mica film capacitors to gamma and fast neutron radiations. Mica capacitors show low gamma radiation response in comparison to fast neutron radiation, because a total dose of kGy order has been given by gamma source and only few cGy dose has been given by fast neutron source.
\end{abstract}

Keywords. Mica film capacitors; ionizing radiation; gamma; neutron; radiation damage.

\section{Introduction}

Research and development work is currently being conducted on radiation damage to insulation materials and a large amount of literature is available on the subject matter (Frederickson et al 1992; Hu et al 1998; Kotomin and Popov 1998). Mica is an extremely stable and excellent insulator material for high voltages. It is resistant to high temperature, thermal and mechanical shock and vibration. Low loss capacitors are sometimes made using mica as dielectric. Mica is also used in X-ray equipments, radiation pyrometer and for radiation insulation. A study focused on the degradation of mica (phlogopite type) film capacitors due to gamma and neutron irradiation has been undertaken for future high-energy experiments. Phlogopite mica is a complex oxide containing $40 \%$ silica, $17 \%$ alumina, $10 \%$ potash, $26.5 \%$ magnesia, $3.5 \%$ ferric oxides, and $3.0 \%$ water. It has a dielectric constant ranging from 5-6 at $15^{\circ} \mathrm{C}$ and has dielectric strength of the order of $2 \times 10^{8} \mathrm{Vm}^{-1}$

The properties of mica film capacitor depend upon the properties of mica material. Our work has not only been focused on the properties of mica film capacitors made using thin film technique but also to analyse their responses to ionizing radiation. The primary purpose of this work is to assess the modification of dielectric material

\footnotetext{
*Author for correspondence (arunpandya123@rediffmail.com)
}

characteristics and capacitance of mica film capacitors (of different capacitor sizes and thickness) that could take place after gamma and neutron irradiation. These capacitors consist of two conducting surfaces of aluminum separated by dielectric insulator i.e. mica. Since the conducting surfaces are metallic, they are not affected by ionizing radiation. But in the dielectric, damage due to radiation interaction, however, influence the capacitance value. Capacitance-voltage measurements have been performed to analyse the irradiation effect on mica capacitors.

\section{Experimental}

\subsection{Theory}

The capacitance of mica film capacitor, prepared in parallel plate configuration is given by

$$
C=\varepsilon_{\mathrm{R}} \cdot \varepsilon_{0} A / d .
$$

Hence, the value of the relative dielectric constant $\left(\varepsilon_{R}\right)$ of mica (insulator) used in the mica film capacitors is

$$
\varepsilon_{\mathrm{R}}=C \times d / \varepsilon_{0} A,
$$

where, $\varepsilon_{0}$ is dielectric constant of air or vacuum, $C$ the capacitance of the specimen, $d$ the thickness of the specimen (mica) and $A$ the area of the specimen electrodes (Ravinder and Vijaya Kumar 2001). 


\subsection{Materials and methods}

Thick phlogopite mica (thickness: 20 and $40 \mu \mathrm{m}(0.7874$ and $1.5748 \mathrm{mil})$ ) was used to prepare the capacitors of dimension $1 \times 1 \mathrm{~cm}^{2}$ and $2 \times 2 \mathrm{~cm}^{2}$ by coating pure aluminum $(99.99 \%)$ of $0.20 \mu \mathrm{m}(0.0079 \mathrm{mil})$ thickness on both sides by thermal evaporation technique. The samples were adequately cleaned before processing. During the deposition, the vacuum was maintained at $\sim 5 \times 10^{-5} \mathrm{mbar}$ and the substrate was heated to $\sim 125^{\circ} \mathrm{C}$. The evaporation rate was maintained between 2.5 and $5 \AA /$ s. Contacts were taken out by using fine copper single wire and silver paste. The lot was divided in four batches and studied. Capacitors of thickness, $20 \mu \mathrm{m}$ with area, $1 \mathrm{~cm}^{2}$ and $4 \mathrm{~cm}^{2}$, were marked as batch A and batch B, respectively. Capacitors of thickness, $40 \mu \mathrm{m}$, with area, $1 \mathrm{~cm}^{2}$ and $4 \mathrm{~cm}^{2}$, were marked as batch C and batch D, respectively.

The capacitance before and after irradiation was measured at room temperature in the frequency range $100 \mathrm{~Hz}-$ $10 \mathrm{MHz}$ by using LF impedance analyser (HP4192 A,

Table 1. Summary of mica film capacitor capacitances before irradiation.

\begin{tabular}{lccc}
\hline & & \multicolumn{2}{c}{ Experimental values of capacitance $(\mathrm{pF})$} \\
\cline { 3 - 4 } Batch & $\begin{array}{c}\text { Theoretical capacitance } \\
\text { [using (1)] }(\mathrm{pF})\end{array}$ & $\begin{array}{c}\text { Devices used for } \\
\text { gamma study }\end{array}$ & $\begin{array}{c}\text { Devices used for } \\
\text { neutron study }\end{array}$ \\
\hline $\mathrm{A}\left(20 \mu \mathrm{m}, 1 \mathrm{~cm}^{2}\right)$ & $233 \cdot 88$ & $319 \cdot 4$ & $163 \cdot 1$ \\
$\mathrm{~B}\left(20 \mu \mathrm{m}, 4 \mathrm{~cm}^{2}\right)$ & 935.51 & $833 \cdot 9$ & $977 \cdot 9$ \\
$\mathrm{C}\left(40 \mu \mathrm{m}, 1 \mathrm{~cm}^{2}\right)$ & 116.94 & 106.9 & $135 \cdot 8$ \\
$\mathrm{D}\left(40 \mu \mathrm{m}, 4 \mathrm{~cm}^{2}\right)$ & 467.76 & $559 \cdot 4$ & $512 \cdot 8$ \\
\hline
\end{tabular}
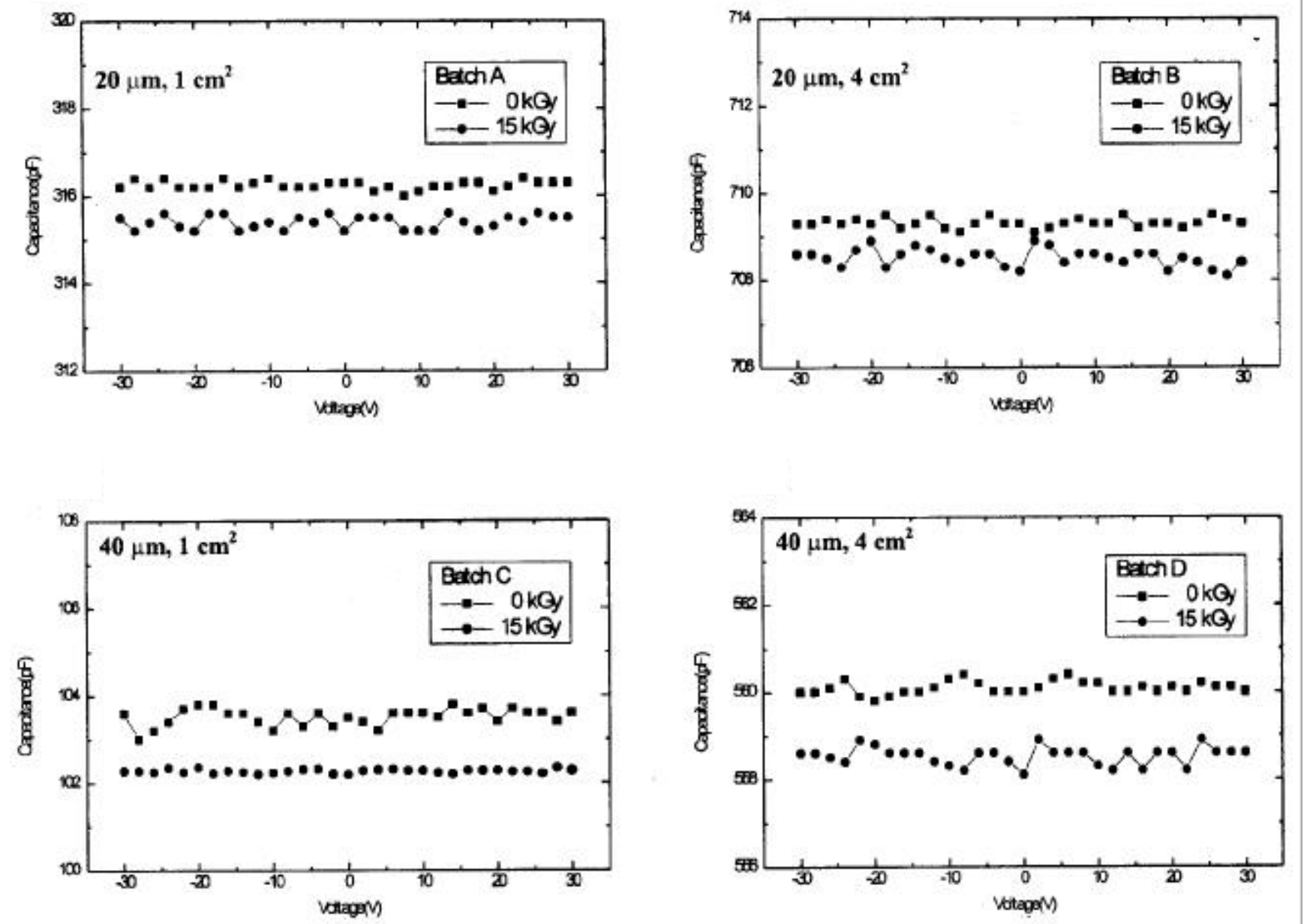

Figure 1. Capacitance-voltage characteristics of mica film capacitors of different batches at $1 \mathrm{MHz}$, before and after gamma irradiation, measured at room temperature. 
Hewlett Packard). Gamma irradiation of mica film capacitors at a dose rate of $0 \cdot 25 \mathrm{kGy} / \mathrm{h}$ from ${ }^{60} \mathrm{Co}$ source was carried out in the Gamma Chamber, GC 900. The capacitors were irradiated with neutrons at low dose rate, $0.3 \mathrm{cGy} / \mathrm{h}$, with flux, $\sim 9.925 \times 10^{7}$ neutrons $/ \mathrm{cm}^{2} \mathrm{~h}$ from a ${ }^{252} \mathrm{Cf}$ neutron source of fluence $2.5 \times 10^{7}$ neutrons/s. In our facility, thermal neutrons were not stopped by using proper screening. So thermal neutron and a parasitic gamma radiation with a dose rate, $0.24 \mathrm{cGy} / \mathrm{h}$, were also given to our devices during neutron irradiation. The samples were unbiased while exposed in both types of irradiations. Post irradiation measurements were made just after irradiation. In each batch, a number of devices were prepared and characterized.

\section{Results and discussion}

Before irradiation, using (2), the experimental average value of the relative dielectric constant $\left(\varepsilon_{R}\right)$ of the phlo-
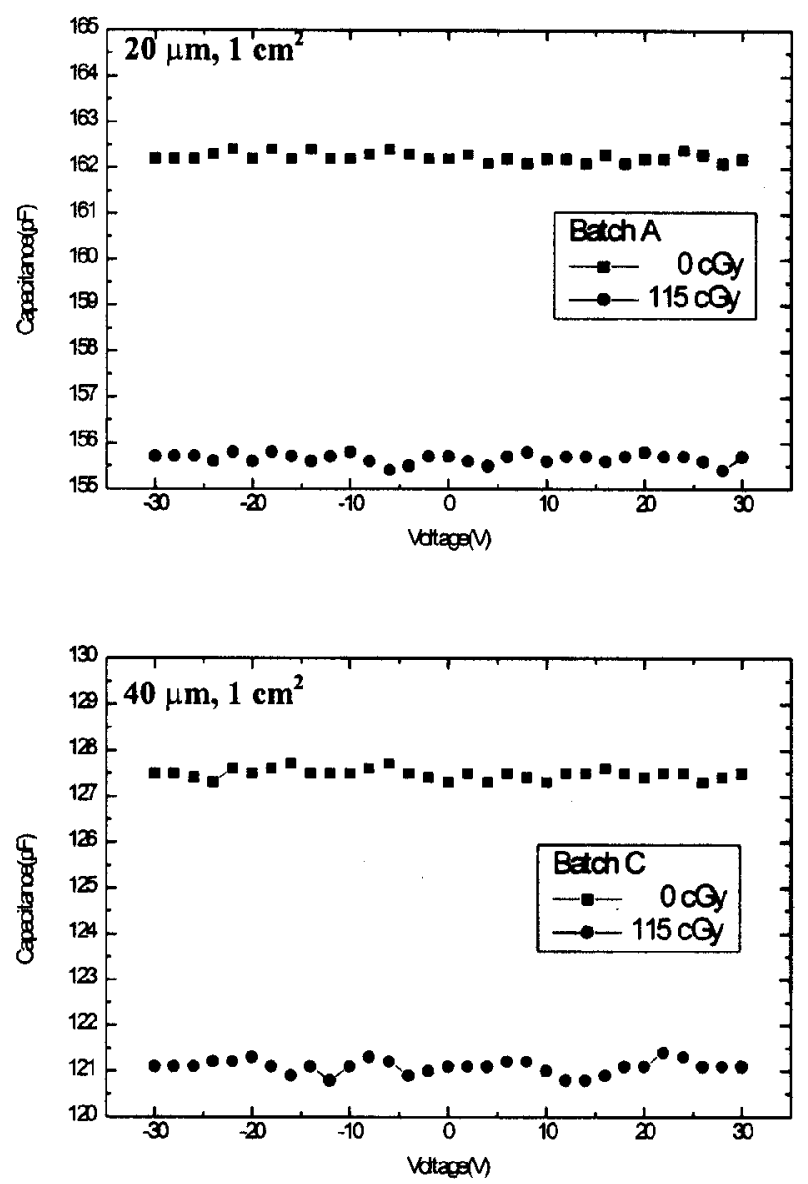

gopite mica (used in our samples) at $1 \mathrm{kHz}$ has been calculated $\left(\varepsilon_{R}=5 \cdot 283\right)$. Taking this value and using (1), table 1 shows the comparative values of the capacitance of mica film capacitors for different batches. These theoretical values are lying between 100 and $1000 \mathrm{pF}$, which are reasonable for our samples, which have been made of 20 and $40 \mu \mathrm{m}$ thick phlogopite mica. Basically, the results indicate that handling and processing of the capacitors during the fabrication steps have not systematically introduced any defects on large scale, such as a long mechanical scratch etc. However, variation in capacitancefrequency behaviour within the batch is due to polyatomic nature of mica and is uncontrollable in the experiment. Our devices have been easily operated up to maximum voltage of $500 \mathrm{~V}$ between the frequency ranges $100 \mathrm{~Hz}$ and $10 \mathrm{MHz}$. Above this voltage, catastrophic breakdown occurs through air. We have not used any special shielding material for our devices because we have restricted our studies for lower voltages. For lower voltages our samples easily comply and no breakdown occurs.
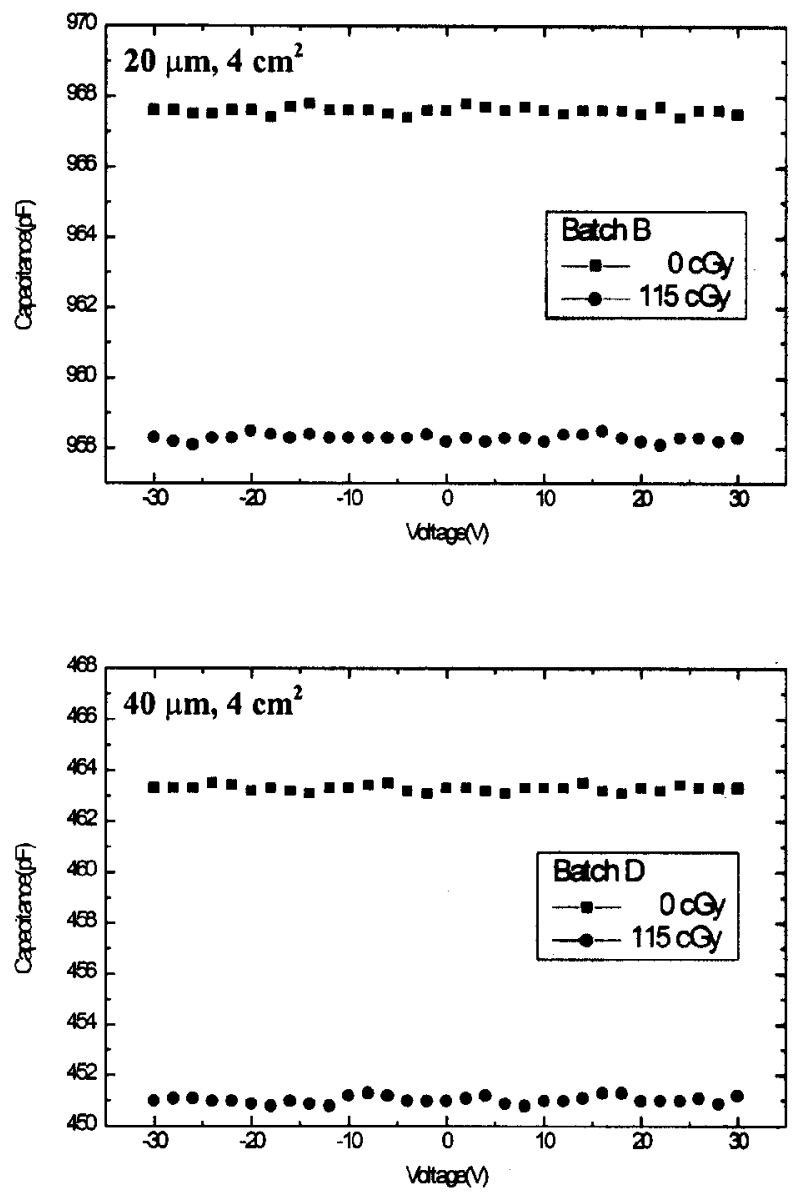

Figure 2. Capacitance-voltage characteristics of mica film capacitors of different batches at $1 \mathrm{MHz}$, before and after neutron irradiation, measured at room temperature. 
Gamma irradiation to a cumulative dose of $15 \mathrm{kGy}$ at a dose rate of $0.25 \mathrm{kGy} / \mathrm{h}$, leads to a minor modification in the capacitance-voltage and capacitance-frequency curves shape. But, even a low dose of $115 \mathrm{cGy}$ at a dose rate of $0 \cdot 3 \mathrm{cGy} / \mathrm{h}$ of fast neutrons cause a decrease in the capacitance in capacitance-voltage curves. Further, the capacitance-frequency curves show a fall of the capacitance after fast neutron irradiation with average energy, $2.5 \mathrm{MeV}$, at frequencies higher than $10 \mathrm{kHz}$. Figure 1 shows the capacitance-voltage characteristics of mica film capacitors of different batches $\mathrm{A}, \mathrm{B}, \mathrm{C}$ and $\mathrm{D}$ at $1 \mathrm{MHz}$ frequency, before and after gamma irradiation. The high frequency capacitance does not change with bias but there is a minor change in $C-V$ after a cumulative gamma dose of $15 \mathrm{kGy}$ at a rate of $0.25 \mathrm{kGy} / \mathrm{h}$. It is seen from the figure that $\sim 2 \mathrm{pF}$ change in capacitance is observed over the entire range for all types of devices after gamma irradiation. Figure 2 compares the capacitance-voltage characteristics of mica film capacitors of different batches A, B, C and $\mathrm{D}$ at frequency, $1 \mathrm{MHz}$, before and after neutron irradiation. The measured capacitance at a given bias after irradiation decreases significantly $(5 \cdot 0-13 \cdot 0 \mathrm{pF})$. In agreement with the result of figure 2 , we have observed an appreciable reduction in the capacitance at $1 \mathrm{MHz}$ after irradiating the samples with only $115 \mathrm{cGy}$ neutron dose at a rate of $0.3 \mathrm{cGy} / \mathrm{h}$.

Mica is a complex oxide having inevitable mobile ionic charges within the oxide. For example, alkali metal ions (particularly $\mathrm{Na}^{+}, \mathrm{Li}^{+}, \mathrm{K}^{+}$, and possibly $\mathrm{H}^{+}$) can be incorporated inadvertently in the oxide during growth or subsequent processing steps. These ions introduce positive ionic charges in the oxide. The oxide also contains trapped charges due to imperfection in the oxides. In addition to these charges, there are also interface traps and fixed charges in the oxide (Streetman 1991). The effect of these charges on the properties of mica is complicated. Incident gamma radiation produces accumulation of trapped charges, and buildup of interface traps and bulk oxide traps in $\mathrm{SiO}_{2}$ oxide (Kjar and Nichols 1975; Chang and Lyon 1986; Pandya et al 2000). Whereas, neutrons cause displacement damage (atoms displaced from their original lattice position by the radiation) in mica material (Ma
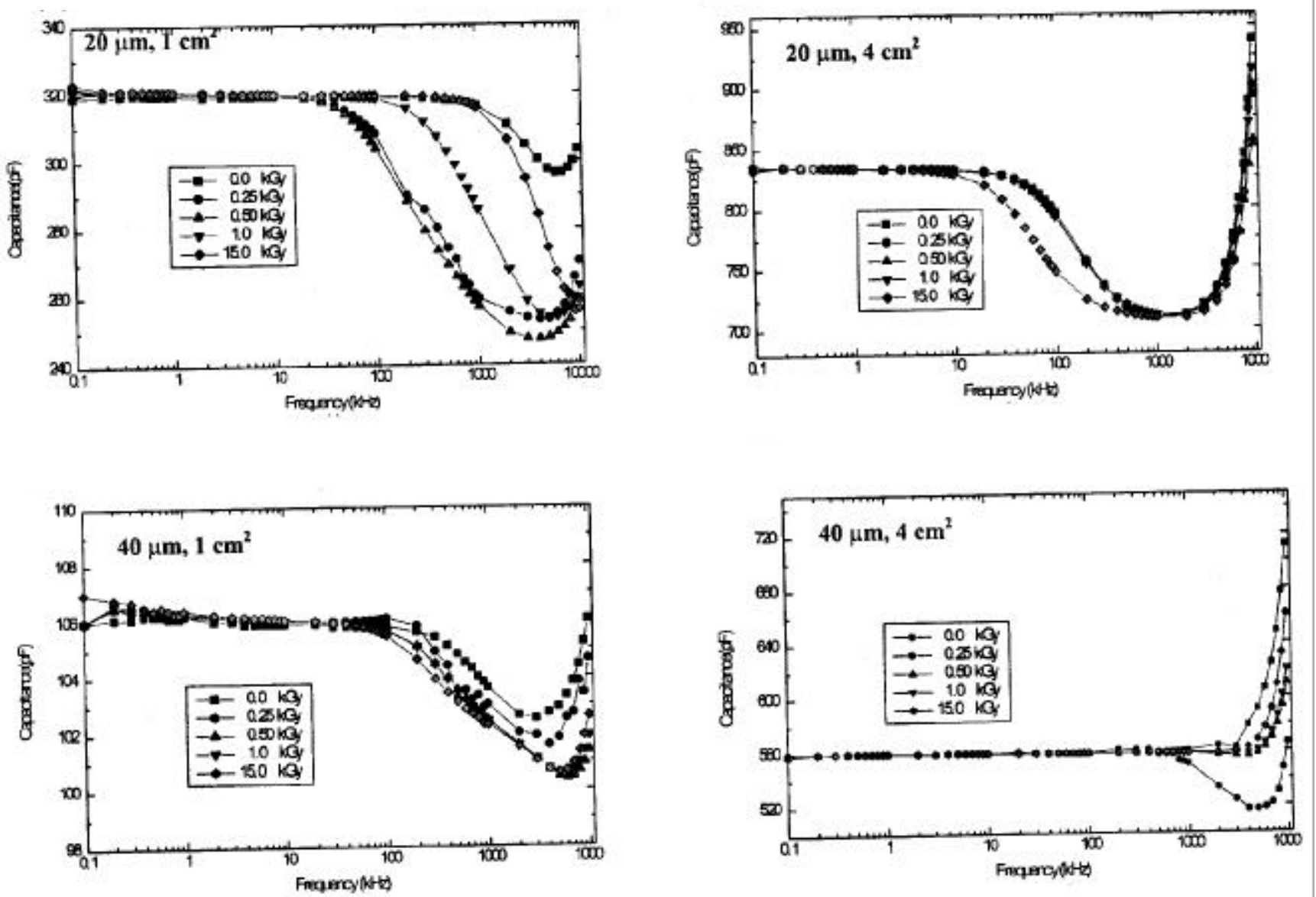

Figure 3. Capacitance-frequency characteristics of the mica film capacitor of different batches at frequencies from $100 \mathrm{~Hz}-$ $10 \mathrm{MHz}$ at an oscillation level 1.000 V. Measurements taken after different gamma doses at room temperature. 
and Dressendorfer 1989). But phlogopite mica has $40 \%$ $\mathrm{SiO}_{2}$ and the interaction probability of gamma is lesser than neutron. Therefore, the effect of gamma is negligible in our samples. As the measured capacitance depends upon the density of free carriers and the density of traps, which have emission rates greater than the frequency of the a.c. test voltage, the reduction in the measured capacitance implies that the density of these carriers have been reduced. Irradiation also causes a decrease in the mobility of carriers due to radiation-induced defects. Therefore, a significant concentration of deep levels has been created in the material due to the neutron fluence. The reduction in free carrier density implies that either acceptor (electron) traps have been introduced or the Fermi level has been lowered, resulting in a lower free carrier concentration. Lowering of the Fermi level will be caused by an increased concentration of deep levels that decreases the chances of electrons to jump into the conduction band.

Figures 3 and 4 illustrate the changes in the capacitance-frequency characteristics before and after the high
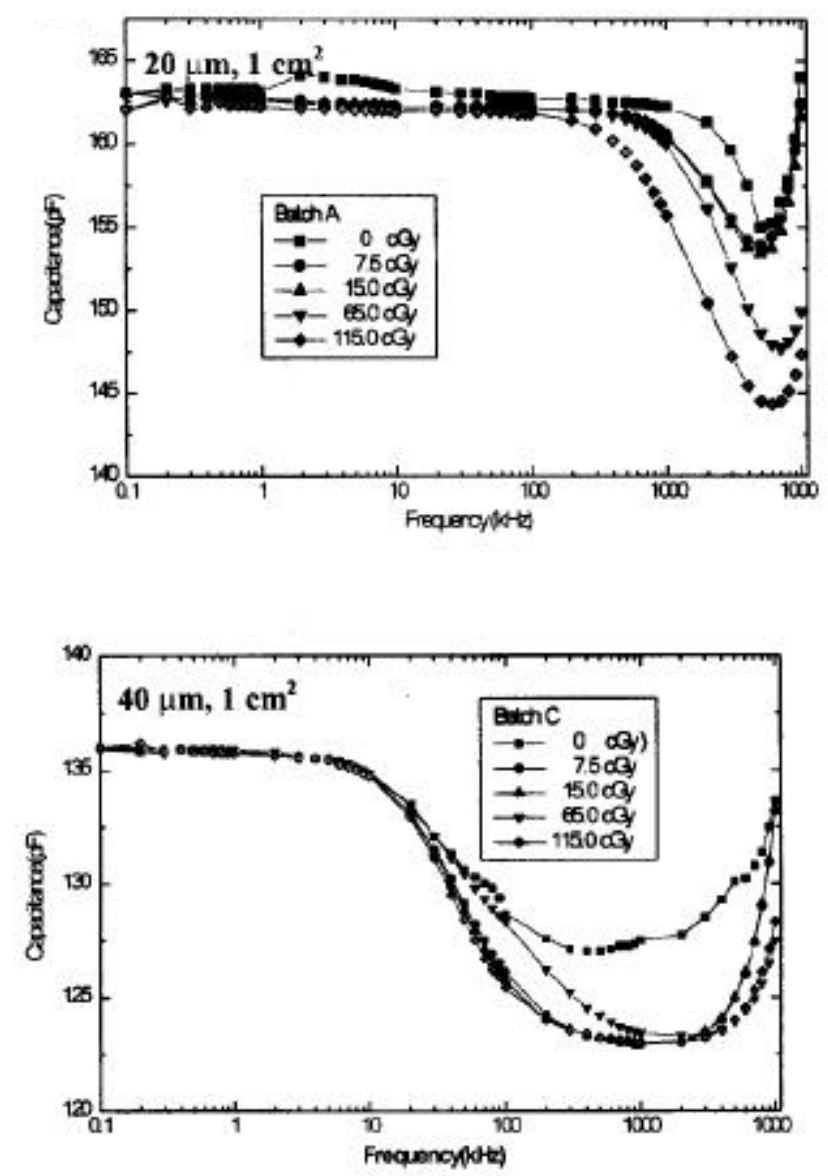

gamma and fast neutron dose irradiation, respectively. The capacitance-frequency relationship shows dependence of capacitance upon the frequency of the test signal used to make the measurement. We observe that both before and after irradiation, there is a turn-around in the capacitance-frequency curves; i.e. the capacitance decreased to a minimum value and then increased from this point. The capacitance-frequency measurements have been done at an oscillation level of $1.000 \mathrm{~V}$. Below $10 \mathrm{kHz}$, the pre and post irradiation values of capacitance in both the figures are indistinguishable. The capacitance at frequencies lower than $10 \mathrm{kHz}$ does not change with irradiation but above $10 \mathrm{kHz}$, the change in capacitance is more. The change in capacitance-frequency curves of figure 3 (where high gamma dose at a high dose rate, $0.25 \mathrm{kGy} / \mathrm{h}$, was given) is not similar to the change of capacitancefrequency curves of figure 4 (where low fast neutron dose at low dose rate, $0.3 \mathrm{cGy} / \mathrm{h}$, was given). High-energy neutrons (fast neutrons with average energy, $2.5 \mathrm{MeV}$ ) produce mobile vacancies in the crystal lattice, thus creating room temperature stable defects, called Frenkel

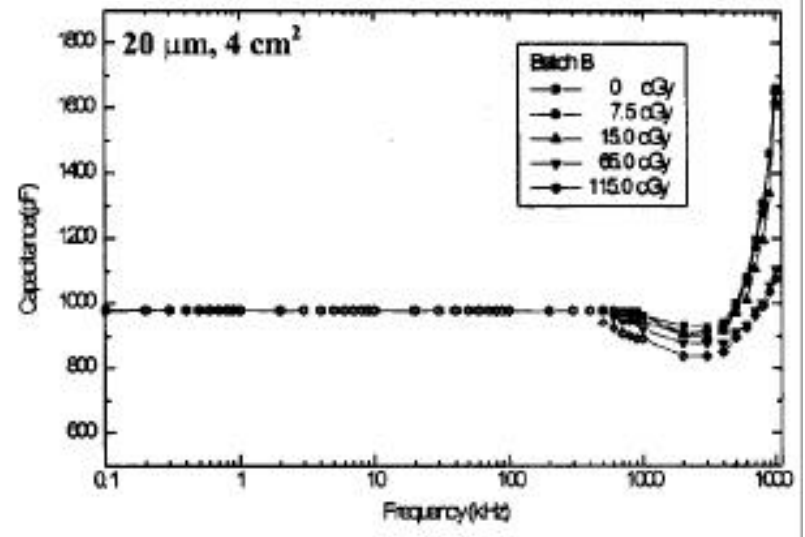

Figure 4. Capacitance-frequency characteristics of the mica film capacitor of different batches at frequencies from $100 \mathrm{~Hz}-$ $10 \mathrm{MHz}$ at an oscillation level 1.000 V. Measurements taken after different neutron doses at room temperature. 
defects and complex defects (Bhatnagar et al 1993). These defects-like pair of vacancies and interstitial cause the degradation of specimen properties. Further, the radiation induced deep levels are introduced, which compensate the material and thus causes the Fermi level to approach mid-band gap.

Mica capacitors have been exposed to gamma radiations of the order of $\mathrm{kGy}$ whereas neutron doses have been given of cGy order. In other words, on an average the gamma radiation induced defects have practically no effect on the capacitive properties of the complex oxide of mica material. This is in agreement with what is reported in similar studies (Anderson et al 1995; Brozek et al 1995). Some modifications of the capacitance-frequency curves have been systematically observed after low dose of neutron irradiation. Figures 1-4 indicate that there is no relative reduction in capacitance for $40 \mu \mathrm{m}$ thick mica film capacitors and $20 \mu \mathrm{m}$ mica film capacitors.

\section{Conclusions}

Mica, being a mineral and inorganic in nature undergoes negligible change due to gamma irradiation in general. A significant change has been observed with neutron irradiation, mainly due to the reason that interaction probability of neutrons, due to its large size, is much more in comparison to gamma. Radiation induced defects by neutrons decrease the dielectric constant of mica that causes to decrease the capacitance of mica film capacitor. Even though these are just the first results we have collected, we may address here a few points as they can be deduced from this work. First of all our data is strictly processrelated and even for the same nominal process lot-to-lot differences have appeared. We have also observed that the post irradiation effects are more at higher frequencies for mica film capacitors.

We conclude that mica capacitors performance in nuclear environment will be different from gamma environment because of more neutron radiation effect, especially at higher frequencies. However, testing under bias condition is needed in order to verify these results in a more realistic and practical radiation environment. The above work indicates that mica film capacitors are in a prominent position as far as lesser effects of gamma radiation are concerned.

\section{Acknowledgements}

Authors would like to acknowledge Sri R K Syal, Director and Dr M P Chacharkar, Group Director, Defence Laboratory, Jodhpur, for the accomplishment of this work. Authors thank Head, NRMA Division, for providing necessary help. Authors are also thankful to Dr N K Srivastava, J.N.V. University, Jodhpur, for fruitful discussions.

\section{References}

Anderson S R, Schrimpf R D, Galloway K F and Titus J L 1995 Microelectron. Reliab. 35603

Bhatnagar P K, Pandya Arun, Reddy A R and Thakur D K 1993 Nucl. Instrum. Meth. Phys. Res. A329 467

Brozek T, Wisniewski R, Beck R B and Jakubowski A 1995 Microelectron. Eng. 28349

Chang S T and Lyon S A 1986 Appl. Phys. Lett. 48136

Frederickson A R, Holeman E G and Mullen E G 1992 IEEE Trans. Nucl. Sci. 391773

Hu Q, Tanaka S, Yoneoka T and Grishmanov V 1998 Nucl. Instrum. Meth. Phys. Res. B141 404

Kjar R A and Nichols D K 1975 IEEE Trans. Nucl. Sci. 222193

Kotomin K A and Popov A I 1998 Nucl. Instrum. \& Meth. Phys. Res. B141 1

Ma T P and Dressendorfer Paul V 1989 Ionizing radiation effects in MOS devices and circuits (New York: John Wiley \& Sons) 1 p. 35

Pandya Arun, Singh B B, Hooda J S, Gupta D and Bhatnagar P K 2000 Proceedings of the 10th international workshop on the physics of semiconductor devices (eds) Vikram Kumar and S K Agarwal (New Delhi: Allied Publishers Ltd.) I 629

Ravinder D and Vijaya Kumar K 2001 Bull. Mater. Sci. 24505

Streetman B G 1991 Solid state electronic devices (New Delhi: Prentice-Hall of India Pvt. Ltd.) pp 310-312 